\title{
A atuação dos burocratas de nível de rua na implementação de políticas públicas no Brasil: uma proposta de análise expandida
}

\author{
FRANCESCO BONELLI ${ }^{12}$ \\ ANTONIO SÉrgio ARAújo FERNANDES ${ }^{2}$ \\ DENILSON BANDEIRA COÊLHO ${ }^{3}$ \\ Jamill da Silva PaLmeIRA ${ }^{2}$
}

${ }^{1}$ Instituto Federal de Educação, Ciência e TeCnologia da Bahia, Campus AVançado de Ubaitaba - BA, Brasil

2 Universidade Federal da Bahia / NúCleo de Pós-Graduação em AdMINISTRAÇÃo, SALVAdor - BA, BrasiL

${ }^{3}$ Universidade de BrasílIa / INSTITUTO de CIÊNCIA PolítICA, BRAsílIA - DF, BRASIL

\begin{abstract}
Resumo
Neste artigo são analisadas as múltiplas dimensões da atuação dos burocratas de nível de rua no contexto brasileiro da implementação de políticas públicas. O objetivo do ensaio é contribuir para uma maior compreensão do tema com uma abordagem analítica expandida. Para tanto, foi realizada uma pesquisa bibliográfica em bases digitais acadêmicas que permitiu identificar e selecionar trabalhos nacionais e internacionais de acordo com critérios metodologicamente definidos. As publicações obtidas foram analisadas e organizadas em razão das seguintes categorias conceituais: discricionariedade, estruturas, ação individual e relações. Da tensão sobre regras e discricionariedade na administração pública, a análise e a interpretação desses textos evidenciaram: a) a necessidade de cotejar, separadamente e em conjunto, três diferentes perspectivas da atuação dos burocratas de nível de rua (a perspectiva estrutural, a de ação individual e a relacional); b) a necessidade de compreender a articulação dessas perspectivas no próprio processo de implementação. Após este trabalho de revisão bibliográfica foram formuladas hipóteses para uma análise expandida da atuação dos burocratas implementadores, traçando-se linhas para pesquisas futuras sobre o tema. Este ensaio contribui para o debate sobre o tema com um construto teórico inédito, que busca integrar as três diferentes perspectivas analíticas apresentadas numa síntese dialética dos conceitos centrais da literatura sobre a implementação de políticas públicas pelos burocratas de nível de rua.
\end{abstract}

Palavras-chave: Burocratas de nível de rua. Implementação de políticas públicas. Brasil. Regras. Discricionariedade.

\section{Street-level bureaucrats' action in the implementation of public policies in Brazil: a proposal for expanded analysis}

\section{Abstract}

This article analyzes the multiple dimensions of street-level bureaucrats' action in the implementation of public policies in the Brazilian context. The study aims to contribute to understand the subject with an expanded analytical approach. Bibliographic research was carried out in academic digital databases, identifying and selecting national and international works, according to methodologically defined criteria. The publications were analyzed and organized according to the following conceptual categories: discretion, structures, individual action, and relations. From the tension regarding rules and discretion in public administration, the analysis and interpretation of these works showed: a) the need to compare, separately and jointly, three different perspectives of street-level bureaucrats' action (structural, individual action and relational perspectives); b) the need to understand the relationship of these perspectives in the implementation process itself. After the bibliographic review, hypotheses were formulated for an expanded analysis of the policy implementers' action, suggesting lines for future research on the subject. This article contributes to the debate on the subject with an unprecedented theoretical construct that seeks to integrate the three different analytical perspectives presented in a dialectical synthesis of the central concepts of the literature on street-level bureaucrats' implementation of public policies.

Keywords: Street-level bureaucrats. Implementation of public policies. Brazil. Rules. Discretion.

\section{La actuación de los burócratas de la calle en la implementación de políticas públicas en Brasil: una propuesta de análisis ampliado}

\section{Resumen}

Este artículo analiza las múltiples dimensiones de la actuación de los burócratas de la calle en el contexto brasileño de la implementación de políticas públicas. El objetivo del ensayo es contribuir a una mejor comprensión del tema con un enfoque analítico ampliado. Para ello, se realizó una investigación bibliográfica en bases digitales académicas que permitió identificar y seleccionar trabajos nacionales e internacionales, de acuerdo con criterios metodológicamente definidos. Las publicaciones obtenidas fueron analizadas y organizadas de acuerdo con las siguientes categorías conceptuales: discrecionalidad, estructuras, acción individual y relaciones. A partir de la tensión sobre las reglas y la discrecionalidad en la administración pública, el análisis y la interpretación de estos textos evidenciaron: a) la necesidad de cotejar, separadamente y en conjunto, tres diferentes perspectivas de la actuación de los burócratas de la calle (la perspectiva estructural, la de acción individual y la relacional); b) la necesidad de comprender la articulación de esas perspectivas en el propio proceso de implementación. Después de este trabajo de revisión bibliográfica, se formularon hipótesis para un análisis ampliado de la actuación de los burócratas implementadores, trazando líneas para futuras investigaciones sobre el tema. Este ensayo contribuye al debate sobre el tema con un constructo teórico sin precedentes, que busca integrar las tres diferentes perspectivas analíticas presentadas en una síntesis dialéctica de los conceptos centrales de la literatura sobre la implementación de políticas públicas por los burócratas de la calle.

Palabras clave: Burócratas de la calle. Implementación de políticas públicas. Brasil. Reglas. Discrecionalidad.

Artigo submetido em 07 de novembro de 2018 e aceito para publicação em 25 de março de 2019.

Os autores agradecem ao Conselho Nacional de Desenvolvimento Científico e Tecnológico (CNPq) pelo apoio por meio do edital Universal e aos revisores anônimos pelas valiosas contribuições. 


\section{INTRODUÇÃO}

A importância da qualidade das instituições do Estado na regulação dos comportamentos humanos, no fornecimento de bens coletivos, na execução e na fiscalização dos serviços públicos, na formulação e na implementação de políticas públicas, bem como no processo de desenvolvimento socioeconômico de um país é um aspecto amplamente reconhecido na literatura (COÊLHO e FERNANDES, 2017; EVANS, 1995; HODGSON, 2006). Entre essas instituições se enquadra a Burocracia, que, na visão de Max Weber, consiste em uma forma organizacional de um sistema sociopolítico administrada de forma hierárquica, com base na autoridade racional-legal, em que as normas prevalecem sobre os interesses individuais e a discricionariedade de seus agentes (PEREIRA e MOTTA, 1987; PIRES, 2009; WEBER, 1968).

Um estudo conduzido por Evans e Rauch (1999) em 35 países em desenvolvimento permite identificar três características estruturais que a Burocracia deve possuir para que seja possível construir um ambiente político-institucional propício ao crescimento econômico: o recrutamento baseado na meritocracia, a possibilidade de promoção interna e a estabilidade profissional.

Pelo exposto, o estudo da Burocracia continua atual e necessário para a compreensão do modo como as políticas formuladas pelo Estado podem traduzir-se no âmbito administrativo. Contudo, trabalhos de sociologia do direito conduzidos desde os anos 1960 por autores como Wilson (1967) e, sucessivamente, pesquisas no campo da ciência política desenvolvidas nas décadas de 1980 e 1990 disseminaram o entendimento de que o estudo das estruturas burocráticas não seria suficiente para compreender a tradução das políticas públicas na prática (DELEON, 1999; MATLAND, 1995; O’TOOLE JUNIOR, 1995; PARSONS, 1995). Lipsky (1980) acrescenta que, para se entender como as políticas públicas funcionam na prática, seria preciso também estudar a fase de implementação, na qual as ações concretas dos burocratas são dirigidas diretamente aos usuários-cidadãos.

Dentre outras publicações, destaca-se o estudo seminal de Lipsky (1980), no qual os burocratas implementadores são identificados como "burocratas de nível de rua": agentes estatais que, diferentemente dos burocratas de médio escalão (diretores, gerentes, coordenadores etc.), prestam seus serviços diretamente ao usuário-cidadão ou monitoram os serviços públicos prestados por terceiros (HAM e HILL, 1993; LIPSKY, 1980). Segundo Lipsky (1980), para os burocratas que atendem diariamente os usuários, chamados na literatura também de burocratas da linha de frente ou burocratas das esquinas (OLIVEIRA, 2012), a exemplo de policiais, assistentes sociais, enfermeiros, médicos, professores, juízes etc., torna-se inevitável adotar ações discricionárias para garantir a aplicação das políticas no plano administrativo.

No processo de implementação de policies, esses agentes precisam adquirir habilidades específicas - tanto técnicoadministrativas como relacionais - para lidar com os diferentes atores envolvidos nas incertezas e ocorrências não previstas nas normas (CURRIE e PROCTER, 2005). As decisões destes burocratas, que frequentemente fazem parte do contexto social em que atuam, podem oscilar dentro de uma margem de discricionariedade relativamente ampla, dependendo do seu grau de autonomia e da existência de regras claras e completas que delimitem comportamentos e tomadas de decisão (LOTTA, 2010, 2014; LOTTA, PIRES e OLIVEIRA, 2014; OLIVEIRA, 2012; PIRES, 2009).

Pesquisas no campo de políticas públicas evidenciam o problema da incompletude de normas: frequentemente as normas legais - fruto de negociação política - mantêm certa imprecisão, indeterminação e ambiguidade na linguagem e na definição dos objetivos (MATLAND, 1995; OLIVEIRA, 2012; ZAHARIADIS, 2007). O problema não resolvido na fase de elaboração da política é, então, transferido do âmbito legislativo para o administrativo, ou seja, para a fase de implementação, deixando margem para interpretação e discricionariedade dos burocratas implementadores (OLIVEIRA, 2012). Segundo Matland (1995), essa ambiguidade de regras e objetivos é uma característica das policies que não deve ser concebida necessariamente como um aspecto negativo. À diferença do posicionamento de estudos que adotam uma abordagem hierárquica (ou top-down) da implementação de políticas públicas (PRESSMAN e WILDAVSKY, 1973; VAN METER e VAN HORN, 1975), a ambiguidade das normas possui certa utilidade, pois, pode favorecer acordos entre atores portadores de posições conflitantes - especialmente na fase de formulação de policies - e impulsionar, durante sua execução, experimentação e aprendizagem de novas técnicas, metodologias e objetivos (MATLAND, 1995).

Nesse contexto, agentes implementadores, diante da acumulação de grande volume de demandas, da insuficiência de recursos e oprimidos pelas engrenagens do sistema burocrático, podem procurar atalhos deliberadamente, moldando e simplificando seu trabalho, criando práticas que permitem o atendimento dos usuários segundo um padrão de qualidade minimamente aceitável (LIPSKY, 1980). Nessa linha de raciocínio, Ham e Hill (1993) destacam, como consequência da atuação dos street-level 
bureaucrats, a adoção de estratégias de sobrevivência e mecanismos psicológicos de enfrentamento que se traduzem na adoção de respostas estereotipadas para os usuários. Ocasionalmente, estes comportamentos podem estar relacionados, de forma oportunista, com o exercício de poder dentro das entidades públicas: profissionais qualificados, como médicos, advogados, arquitetos, professores etc., podem agir - por conta do seu status - em benefício de interesses corporativos, desvirtuando a missão das organizações burocráticas (HAM e HILL, 1993).

Autores como Maynard-Moody e Musheno (2000) destacam que as normas podem constituir uma barreira indesejada entre a ação desses agentes e as demandas dos usuários-cidadãos. Segundo as narrativas trazidas pelos próprios burocratas de nível de rua, os implementadores, no lugar de se colocarem como executores obedientes de regulamentos, podem adotar intencionalmente seu julgamento pragmático - embasado em valores comunitários, experiência direta e sabedoria transmitida - e priorizar o atendimento responsável às necessidades dos cidadãos, justificando suas decisões em virtude das melhorias alcançadas na execução da política, apesar de isso se traduzir num trabalho mais difícil, perigoso, pouco valorizado etc. (MAYNARD-MOODY e MUSHENO, 2000).

Mais recentemente, o estudo de Lotta, Pires e Oliveira (2014), embora voltado para os burocratas de médio escalão, permite compreender como a atuação dos agentes implementadores se desdobra em diferentes perspectivas, como a estrutural, a de ação individual e a relacional, discutidas oportunamente mais adiante.

Os avanços no conhecimento do tema evidenciam a complexidade do processo de implementação, o qual, além de ser analisado da perspectiva weberiana de burocracia, com suas estruturas e regras, precisa ser estudado da ótica da atuação dos burocratas de nível de rua e de suas interações com os demais atores envolvidos (LOTTA, 2010, 2014; OLIVEIRA, 2012).

Apesar desses progressos, o recente trabalho de Ferreira e Medeiros (2016), que sistematizou a literatura sobre os fatores comportamentais do agente implementador de políticas públicas, mostra a fragmentação entre as diferentes perspectivas que compõem o estado da arte sobre a implementação de políticas públicas. Eles demonstram que, até então, as diferentes perspectivas adotadas na implementação de políticas públicas, conforme a conveniência dos autores, resultam em análises que acabam por se excluírem mutuamente (FERREIRA e MEDEIROS, 2016). Acredita-se que esse seja um fator limitador para uma compreensão mais plena e abrangente do fenômeno, o qual poderia ser mais bem explicado integrando-se as diferentes abordagens, desde que seja possível justificar a junção das teorias que as sustentam.

Diante desse quadro, este trabalho se justifica pela proposta de inserir na agenda da Administração Pública brasileira estudos que, valendo-se do cotejamento das diferentes perspectivas teóricas e da avaliação de sua compatibilidade, permitam compreender como se articulam as diversas dimensões da atuação dos burocratas de nível de rua e seus efeitos sobre o próprio processo de implementação de policies.

O objetivo deste ensaio, então, é contribuir para pautar pesquisas futuras que adotem uma abordagem analítica expandida que permita captar, com base no dilema entre controle e discricionariedade, as múltiplas dimensões da atuação dos burocratas de nível de rua e sua articulação na implementação de políticas públicas nacionais.

Para tanto, foi realizada uma pesquisa bibliográfica (GIL, 2007; GRAY, 2012), a qual contemplou as seguintes etapas: a) busca e seleção de trabalhos nacionais e internacionais sobre o tema; b) exame das referências contidas nessas obras, quando aderentes ao tema; c) identificação de categorias teóricas relevantes; d) análise, interpretação e avaliação crítica dos textos escolhidos. O procedimento utilizado se justifica pela natureza do problema, o qual consiste no aprofundamento de um debate teórico relevante no campo de Administração Pública.

A pesquisa bibliográfica foi realizada em bases digitais acadêmicas, buscando-se pelo título, resumo e palavras-chave; foram utilizados os termos em língua inglesa "street-level bureaucrats", "public policy" e "implementation", combinados com o auxílio do operador booleano "AND", e os correspondentes termos em língua portuguesa "burocratas de nível de rua", "políticas públicas" e "implementação", com o auxílio do mesmo operador "AND". Quanto ao período de publicação das obras procuradas, não foi aplicado nenhum recorte temporal às buscas

Com base nestes critérios, inicialmente foram recolhidas 71 referências, as quais sofreram duas reduções: a primeira visando a adequação ao tema da pesquisa, pela análise dos títulos, dos resumos e das palavras-chave, o que reduziu o número de textos a 36; a segunda pela subtração das duplicidades, restando 29 publicações. Contudo, observando-se as referências das obras recolhidas na primeira etapa, mais 11 artigos foram identificados e acrescentados aos 29 por sua aderência ao tema, o que resultou no total final de 40 textos (observamos que não fazem parte do total final as obras utilizadas para discutir o 
conceito de implementação de forma geral). Essas publicações foram analisadas integralmente e organizadas em virtude de quatro categorias conceituais centrais do debate acadêmico: 1) discricionariedade; 2) estruturas (compreensiva dos conceitos de organizações, hierarquias e regras); 3 ) ação individual (compreensiva dos conceitos de agência, stewardship e variáveis cognitivas); 4) relações (compreensiva dos conceitos de interações e mediação). No Quadro 1, estão reportadas as principais referências, organizadas em razão das quatro categorias conceituais que serão discutidas mais adiante neste ensaio.

\section{Quadro 1}

\section{Principais publicações organizadas por categoria conceitual}

\begin{tabular}{|c|l|}
\hline Categoria conceitual & \multicolumn{1}{c|}{ Referências } \\
\hline Discricionariedade & $\begin{array}{l}\text { Barrett (2004); Davis (1969); Floyd e Wooldridge (1992); Huising e Silbey (2011); } \\
\text { Hupe e Hill (2007); Lipsky (1980); Lotta (2010, 2014); Lotta, Pires e Oliveira (2014); } \\
\text { Pires (2009); Wilson (1967). }\end{array}$ \\
\hline Estruturas & $\begin{array}{l}\text { Coêlho e Fernandes (2017); Evans e Rauch (1999); Lupia e McCubbins (1994); } \\
\text { March e Olsen (2006); Pereira e Motta (1987); Wise (2004). }\end{array}$ \\
\hline Ação individual & $\begin{array}{l}\text { Alchian e Demsetz (1972); Cline (2000); Davis, Schoorman e Donaldson (1997); } \\
\text { Elmore (1979); Fama e Jensen (1983); Evans e Rauch (1999); Kluvers e Tippett } \\
\text { (2011); Lima e D’Ascenzi (2013); Lupia e McCubbins (1994); Maynard-Moody e } \\
\text { Musheno (2012, 2015); Moe (1984); Donaldson e Davis (1991); Muller e Surel } \\
\text { (2002); Niskanen (1971); Osborne e Gaebler (1992); Pollitt (1995); Van Slyke (2006). }\end{array}$ \\
\hline Relações & $\begin{array}{l}\text { Abers e Von Bülow (2011); Alexander, Lewis e Considine (2011); Berk, Galvan e } \\
\text { Hattam (2013); Coêlho, Cavalcante e Turgeon (2016); Huising e Silbey (2011); Keiser } \\
\text { (2010); Lima e D’Ascenzi (2013); Lotta (2010, 2014, 2018); Lotta, Pires e Oliveira } \\
\text { (2014); Pires (2009); Viana (2017). }\end{array}$ \\
\hline
\end{tabular}

Fonte: Elaborado pelos autores.

Quanto à estrutura deste ensaio, além desta introdução, na qual são definidos o tema e o objetivo do trabalho, na próxima seção discute-se a implementação de policies como tema relevante no campo de Administração Pública. Na terceira seção, apresenta-se o debate existente na literatura nacional e internacional sobre o dilema entre regras e discricionariedade da burocracia. Em seguida, na quarta seção, são apresentadas e justapostas as diferentes perspectivas adotadas para analisar a atuação dos burocratas implementadores de políticas públicas, correspondentes a três das quatro categorias conceituais (estruturas, ação individual e relações) já utilizadas para a organização dos textos obtidos na pesquisa bibliográfica. Nesta quarta seção, valendo-se das contribuições das publicações selecionadas, são formuladas hipóteses para a formação de uma análise expandida sobre o tema, traçando linhas para pesquisas futuras. Na quinta seção, é apresentada uma justificativa teórica, devidamente fundamentada, que permite juntar as diferentes abordagens e suas respectivas teorias no construto teórico proposto. Na sexta e última seção, são feitas as considerações finais.

\section{A IMPLEMENTAÇÃO DE POLÍTICAS PÚBLICAS E O CAMPO DE ADMINISTRAÇÃO PÚBLICA}

No Brasil, os estudos de políticas públicas, apesar de certa expansão ocorrida desde a década de 1990, são considerados incipientes, devido à existência de uma multiplicidade de abordagens pouco desenvolvidas, à falta de coerência das linhas de pesquisa e à dispersão dos assuntos estudados.

De fato, é uma área pouco institucionalizada devido à debilidade dos estudos de Administração Pública no país, e excessivamente concentrada nas análises dos processos decisórios (FARIA, 2003; LOTTA, 2014). Mais especificamente, existem lacunas relevantes no plano teórico, especialmente no estudo das fases de implementação e avaliação, assim como na compreensão dos mecanismos que influenciam no desempenho das policies (FARIA, 2003; HILL, 2003; LOTTA, 2014; PIRES, 2009).

Apesar de os modelos tradicionais ainda prevalecerem na literatura, houve uma evolução dos estudos sobre o ciclo de políticas públicas e do próprio conceito de implementação de políticas públicas. Na análise de implementação de políticas públicas, é importante distinguir entre as abordagens top-down (mais tradicionais) e as abordagens bottom-up. 
Por um lado, na literatura main-stream dos anos 1970, a implementação é definida como a relação - linear e hierárquica de causa-efeito entre os objetivos fixados na formulação e as ações realizadas para alcançá-los (BARRETT, 2004; PRESSMAN e WILDAVSKY, 1973; VAN METER e VAN HORN, 1975). A abordagem top-down mostra, ainda, uma clara separação wilsoniana entre política e administração: as políticas formuladas por agentes políticos devem ser simplesmente executadas por meio da burocracia (WILSON, 1887).

Segundo a detalhada e empiricamente rigorosa revisão do estado da arte sobre implementação de políticas públicas conduzida por Saetren (2014), a primeira geração de estudos sobre implementação é caracterizada por trabalhos de natureza exploratória em um campo ainda relativamente virgem. A principal preocupação dessas pesquisas, que adotam prevalentemente a estratégia de estudo de caso único de tipo qualitativo (SAETREN, 2014), é explicar por que os planos e os objetivos definidos na fase de formulação de uma política pública não se realizam na sua aplicação, isto é, compreender as causas do gap existente entre o que é planejado e o que é, de fato, executado. Os principais expoentes dessa primeira geração da pesquisa sobre implementação são Pressman e Wildavsky (1973), cujo argumento central é de que a complexidade do próprio processo de implementação seria a causa principal das falhas observadas na execução da policy. Embora a maior parte destes trabalhos da primeira geração tenham sido publicados na década de 1970, segundo Saetren (2014), sua inauguração não coincidiu com o trabalho de Pressman e Wildavsky (1973). De fato, antes da década de 1970 foram publicadas quase duas dezenas de artigos sobre o tema, quatro dos quais remontam à segunda metade dos anos 50 (SAETREN, 2014).

Por outro lado, antes e depois de 1980 acontece uma transição entre a primeira e a segunda geração de estudos sobre a implementação (SAETREN, 2014). Na segunda geração, na qual se destaca o estudo já citado de Lipsky (1980), os motivos do sucesso ou insucesso da execução dos programas de políticas públicas são explicados mediante a adoção de novos modelos analíticos, em virtude dos encontros que acontecem entre o Estado e os usuários, na linha de frente, onde as policies são efetivamente aplicadas pelos burocratas implementadores (perspectiva bottom-up). Os estudos da segunda geração são caracterizados por uma evolução dos modelos teórico-analíticos e dos paradigmas metodológicos adotados, dentre os quais começam a prevalecer os estudos comparativos, especialmente de tipo quantitativo, em detrimento dos estudos de caso único (SAETREN, 2014).

Desde o final da década de 1980, uma terceira geração de estudos vem concebendo a implementação como processo que se desenvolve gradativamente por meio da interação dos vários atores envolvidos, tendo como ponto de partida as intenções de governo, ou expectativas políticas, e como ponto final a percepção do impacto das políticas públicas realizadas (MATLAND, 1995; O'TOOLE JUNIOR, 1995; PARSONS, 1995). Na prática, as policies são criadas pelos agentes implementadores à medida que elas são executadas (DELEON, 1999; FARIA, 2012). Nessa ótica, os processos importam mais do que os planos iniciais e os resultados não podem ser previstos antecipadamente, enquanto suscetíveis a mudanças e contingências (LOTTA, 2014; MAJONE e WILDAVSKY, 1984).

Portanto, segundo as abordagens da terceira geração que desenvolvem um trabalho de síntese entre perspectivas topdown e perspectivas bottom-up (BARRETT, 2004) ou focam na relação dialética entre a formulação e a implementação, "the policy-action relationship" (BARRETT, 2004, p. 256), pode-se entender a implementação como um processo de execução e de adaptação, mediado pelo Governo e seus agentes, das soluções desenhadas inicialmente na etapa de formulação (LIMA e D'ASCENZI, 2013). Segundo Saetren (2014), na terceira geração de estudos são reconhecidos progressos maiores no plano metodológico do que no plano teórico, considerando-se que as questões teóricas teriam evoluído de forma "muito mais lenta e incremental" (SAETREN, 2014, p. 84, tradução dos autores). Nessa geração de estudos, segundo Saetren (2014), acentua-se a tendência que consiste na adoção de estratégias metodológicas comparativas de tipo quantitativo, baseadas em uma lógica hipotético-dedutiva, no lugar de estratégias indutivas de tipo qualitativo. Esse aspecto, na visão de O’Toole Junior (2000), representaria um indicador de um campo de estudos que já se encontra na sua fase de maturidade.

Considerando-se o debate acerca das abordagens top-down e bottom-up, e os resultados alcançados ao longo de cinco décadas de pesquisa sobre a implementação, observa-se que alguns dos principais estudiosos do tema, entre os quais os próprios Saetren (2014) e O'Toole Junior (2000), concordam que ainda há muitos progressos a se realizarem, especialmente no plano teórico. Na mesma linha de raciocínio de O’Toole Junior (2000), entende-se que a pesquisa científica sobre a implementação de políticas públicas requer modelos analíticos parcimoniosos que permitam justapor e, se possível, integrar perspectivas teóricas diferentes. 
Portanto, com o objetivo de superar a fragmentação das diferentes perspectivas analíticas e obter uma compreensão mais abrangente do processo de implementação, propõe-se incluir na análise, além das perspectivas estrutural e de ação individual (ou agência), as redes de organizações e indivíduos que compõem o sistema, do ponto de vista de suas interações (LOTTA, 2014, 2018), tendo-se em conta também a discricionariedade dos agentes públicos - um problema já levantado na década de 1960, especialmente no âmbito da sociologia do direito e da sociologia das organizações (CAVALCANTI, LOTTA e PIRES, 2018).

A proposta teórica deste trabalho requer um olhar mais crítico sobre a fase de formulação das políticas públicas, frequentemente elaborada pela barganha entre posições divergentes de diversos atores políticos, o que resulta em objetivos imprecisos, contraditórios, repletos de omissões e reticências (OLIVEIRA, 2012; ZAHARIADIS, 2007). Por conseguinte, surge a necessidade de essas lacunas serem resolvidas na fase de implementação, ou seja, no plano administrativo, por meio da ação dos burocratas implementadores, que atuam como mediadores, centralizadores de informações e intermediários estratégicos entre os agentes políticos e os cidadãos (LOTTA, PIRES e OLIVEIRA, 2014; OLIVEIRA, 2012).

Defende-se, então, a importância de uma análise da implementação de policies no nível micro, com foco no exercício da discricionariedade por parte dos burocratas da linha de frente, agentes capazes de tomar decisões voltadas para as demandas dos usuários-cidadãos (MAYNARD-MOODY e MUSHENO, 2000). Por outro lado, é necessário também analisar cuidadosamente possíveis comportamentos oportunistas dos agentes públicos, os quais podem desviar voluntariamente as finalidades de suas funções, contrariando normas e procedimentos estabelecidos e afetando a coordenação entre formulação e implementação de políticas (COÊLHO e FERNANDES, 2017; FLOYD e WOOLDRIDGE, 1992; OLIVEIRA e ABRUCIO, 2011).

\section{O DILEMA ENTRE REGRAS E DISCRICIONARIEDADE NA ATUAÇÃO DA BUROCRACIA DE NÍVEL DE RUA}

O debate sobre o controle e a discricionariedade da burocracia foi aberto inicialmente nos campos da sociologia do direito e da sociologia das organizações, poucos anos antes de Lipsky apresentar sua teoria em 1969 "no encontro anual da American Association of Political Science (APSA)" (CAVALCANTI, LOTTA e PIRES, 2018, p. 229). 0 debate se popularizou na literatura da Administração Pública com o artigo do próprio Lipsky (1980) sobre os comportamentos dos street-level bureaucrats. Conforme apontado por Pires (2009), em literatura, há controvérsias sobre a atuação dos burocratas implementadores de políticas públicas: discricionariedade, por um lado, e controle, numa visão weberiana do Estado, por outro lado.

Para compreender melhor o termo "discricionariedade", pode se utilizar a definição de Davis $(1969$, p. 4), segundo a qual “[...] um funcionário público tem discricionariedade onde quer que os limites efetivos de seu poder deixem-no livre para fazer uma escolha entre possíveis cursos de ação e inação". Da parte de Wilson (1967), o conceito de controle define a capacidade de a burocracia cumprir os objetivos de governo definidos nas políticas públicas.

Segundo Barrett (2004), autora declaradamente influenciada pela teoria da estruturação de Giddens (1994), para compreender a discricionariedade é importante identificar o papel dos agentes que conhecem por dentro o sistema em que atuam: esses conhecimentos permitem aos indivíduos ampliar sua capacidade de negociação e seu poder discricionário, no âmbito do próprio processo de implementação, para desafiar ou defender o status quo de acordo com seus valores e interesses.

Na visão de Hupe e Hill (2007), a existência de regras não impede o exercício da discricionariedade por parte dos burocratas de nível de rua. Para esses autores, qualquer tipo de norma - especialmente aquela que regulamenta assuntos complexos, como acontece em várias áreas de políticas públicas - precisa ser interpretado e aplicado à situação fática. Portanto, o exercício da discricionariedade é essencial na execução de policies diante da necessidade de tomar decisões que atendam ou excluam potenciais usuários ou beneficiários de serviços públicos (HUPE e HILL, 2007).

Lotta (2010) evidencia a existência de lacunas teóricas na compreensão das ações dos agentes implementadores e nos fatores que as influenciam: a autora analisa os comportamentos dos street-level bureaucrats e os efeitos de sua atuação na implementação de políticas, considerando, também, a influência de fatores institucionais que limitam a discricionariedade. A implementação é definida como um "[...] complexo processo que envolve pessoas, vontades, necessidades, poder, recursos, disputas, conhecimentos e desconhecimentos" (LOTTA, 2010, p. 15). Adicionalmente, a implementação caracteriza-se pelas comunicações e interações dos burocratas com os usuários, portanto, consiste em um processo de adaptação e de mediação entre Estado e Sociedade, sobretudo devido à ação dos agentes implementadores (LOTTA, 2010). Na prática, interesses 
institucionais, organizacionais, individuais e relacionais podem se sobrepor e alterar os resultados da implementação de policies, chegando-se a aplicar a mesma política pública de maneiras diferentes (LOTTA, 2014; LOTTA, PIRES e OLIVEIRA, 2014).

Numa etnografia conduzida na Eastern University, Huising e Silbey (2011) definem como "regulação relacional” a abordagem utilizada pelos gerentes para administrar o descompasso entre o desenho e a aplicação da legislação: o sucesso desses agentes não consiste em anular o gap, mas em adequar as regras à complexidade e à incerteza do ambiente local e em manter as atividades organizacionais dentro de uma faixa de variação próxima às especificações regulatórias iniciais.

Na mesma linha de raciocínio, Pires (2009) compara os diferentes modelos de gestão - gerencialista versus experimentalista utilizados na fiscalização do trabalho em Pernambuco, mostrando seu impacto nos respectivos resultados da implementação. A pesquisa aponta que uma abordagem menos vinculada a regras e a objetivos/metas predefinidos e mais aberta à aplicação de "táticas diversificadas" e de soluções elaboradas conjuntamente com cidadãos, trabalhadores, sindicados, empresários, outros entes públicos etc. demonstra ser mais eficiente na resolução de problemas complexos (PIRES, 2009, p. 168).

Por outro lado, estudiosos como Lupia e McCubbins (1994) analisaram o problema da delegação de policies do legislativo (principal) para o executivo (agentes): a supervisão do legislativo - nas duas modalidades direta e centralizada (police patrols) ou indireta e decentralizada (fire-alarms) - é o meio mais comum para reduzir o impacto do problema de agência. Segundo os autores, a condição para que a delegação se constitua como meio eficaz na implementação de políticas públicas e não se torne uma forma de abdicação é que os legisladores saibam desenhar instituições que favorecem o aprendizado com base na supervisão (LUPIA e MCCUBBINS, 1994).

Na mesma perspectiva, o recente trabalho de Coêlho e Fernandes (2017) sobre o Programa Bolsa Família demonstra que regras formais, quando compreensíveis para os implementadores e para os usuários-cidadãos, podem atuar como instrumento de modelagem comportamental dos atores envolvidos, favorecendo o aprendizado na relação principal-agentes, melhorando a coordenação de políticas e beneficiando a gestão de policies.

Menciona-se também que o excesso de autonomia pode produzir diferenças excessivas nos resultados alcançados por entidades do mesmo setor (FLOYD e WOOLDRIDGE, 1992), como aconteceu em hospitais públicos paulistas devido à elevada adaptação das normas às necessidades locais (OLIVEIRA e ABRUCIO, 2011).

Com base nos diferentes posicionamentos encontrados na literatura, percebe-se a necessidade de aprofundar a análise da implementação de políticas públicas pelo prisma dos burocratas de nível de rua. Por esse motivo, na próxima seção, serão apresentadas e justapostas três diferentes perspectivas analíticas sobre a atuação da burocracia de nível de rua, e formuladas hipóteses que possam contribuir para compreender o processo de implementação de políticas públicas nacionais, traçando-se linhas para pesquisas futuras sobre o tema. Vale observar que a categoria conceitual "Discricionariedade", já discutida nesta seção, não está entre as três perspectivas analíticas apresentadas a seguir, pois compreende-se que ela se realiza na tensão dialética entre estrutura e agência moldada pelas relações entre os agentes (BARRETT, 2004); sendo assim, ela representa um conceito transversal que se relaciona com cada uma das perspectivas analíticas da atuação dos burocratas de nível de rua discutidas na próxima seção.

A definição das perspectivas apresentadas a seguir é fruto de um esforço de síntese voltado para a construção de um modelo, ao mesmo tempo, abrangente e parcimonioso que possa orientar a realização de pesquisas empíricas necessárias no Brasil para uma melhor compreensão da implementação de políticas públicas nacionais.

\section{PERSPECTIVAS PARA UMA ANÁLISE EXPANDIDA DA ATUAÇÃO DOS BUROCRATAS DE NÍVEL DE RUA}

Nesta seção, são discutidas, com base na literatura selecionada, a perspectiva estrutural, a perspectiva de ação individual e a perspectiva relacional, já adotadas por Lotta, Pires e Oliveira (2014) na análise da atuação dos burocratas de médio escalão. Contudo, aqui elas serão utilizadas na observação da atuação dos burocratas de nível de rua, e permitirão identificar possíveis caminhos para o avanço da investigação sobre o tema. Ressalta-se que as três perspectivas mencionadas correspondem às três distintas modalidades de governança organizacional, estudadas na área de Teoria das Organizações, classificadas em hierarquia, mercado e redes (LOTTA, PIRES e OLIVEIRA, 2014; MÉNARD, 2012; WILLIAMSON, 1985, 1996). Adicionalmente, observa-se que trabalhos recentes sobre os burocratas de nível de rua no processo de implementação identificam os fatores 
que moldam o comportamento dos próprios agentes implementadores, agrupando-os em três grandes categorias: fatores gerenciais, pessoais e relacionais, além dos fatores institucionais (FERREIRA e MEDEIROS, 2016). Entende-se que é possível estabelecer analogias entre fatores gerenciais, pessoais e relacionais e, respectivamente, perspectiva estrutural, de ação individual e relacional.

A seguir, os principais textos selecionados para este ensaio - conforme o Quadro 1 apresentado anteriormente - são apresentados e organizados com o objetivo de discutir as três perspectivas analíticas (estrutural, de ação individual e relacional), cada uma correspondente a uma diferente abordagem teórica. $O$ intuito dessa discussão é construir o argumento central sobre a articulação e a complementariedade das três perspectivas que analisam a atuação dos burocratas de nível de rua de ângulos diferentes, mas não necessariamente excludentes.

A perspectiva estrutural refere-se à obediência dos agentes a regras formais, em consequência da posição ocupada na hierarquia burocrática e ao cumprimento de obrigações e tarefas associadas ao cargo assumido na respectiva organização, em conformidade com a visão weberiana (LOTTA, PIRES e OLIVEIRA, 2014). Para este fim, torna-se necessário conhecer e analisar a organização da agência em questão, sua estrutura e suas normas.

Conforme apontado por March e Olsen (2006), os atores de certa instituição podem tender a alinhar suas ações com as normas vigentes, consideradas, segundo os entendimentos comuns, naturais, justas, esperadas e legítimas. As normas incorporam crenças, expectativas institucionais, práticas, rotinas, hábitos, códigos de conduta etc., consolidados ao longo do tempo e socialmente aceitos. Destarte, esses atores, em lugar de basear suas decisões em cálculos de custo-benefício, reconhecem seu papel organizacional e adaptam seus comportamentos às normas prescritas, seguindo a "lógica da adequação", isto é, escolhendo, em uma situação específica, o curso de ação que mais se encaixa numa determinada previsão normativa (MARCH e OLSEN, 2006). Adicionalmente, Wise (2004) ressalta a preponderância que o cumprimento do interesse público assume na atuação dos burocratas, os quais se encontram fortemente condicionados pelos papeis institucionais predefinidos.

No âmbito dessa perspectiva estrutural, poderiam ser enquadrados os fatores gerenciais, que, segundo Ferreira e Medeiros (2016, p. 790), incluem o conjunto de "[...] recursos, sistemas de controle, [...], padrões de desempenho" e outros mecanismos utilizados, principalmente no âmbito organizacional, pelos agentes políticos e pelos agentes públicos de alto e médio escalão para orientar a ação dos burocratas implementadores em direção aos objetivos estabelecidos. Porém, segundo autores como May e Winter (2007) e os próprios Ferreira e Medeiros (2016), a influência desses fatores gerenciais sobre o comportamento dos burocratas implementadores é muito limitada, devido essencialmente à distância entre os atores que ocupam os níveis hierarquicamente superiores e o plano onde as decisões são tomadas e as ações são realizadas no cotidiano. Por esse motivo, os fatores gerenciais não serão contemplados nos pressupostos colocados a seguir.

Além dos aspectos identificados acima, a qualidade das regras assume uma função importante, pois, normas bem escritas e constantemente melhoradas favorecem a observância e a aplicação de policies, bem como a coordenação entre os atores envolvidos, podendo resultar em um maior grau de desempenho dos serviços prestados à coletividade (COÊLHO e FERNANDES, 2017). Entende-se, então, a importância da aderência dos burocratas de nível de rua aos objetivos e às regras definidas na política pública para sua implementação. Assim sendo, é possível supor que a aderência dos burocratas de nível de rua às regras e às estruturas estabelecidas afeta a implementação de políticas públicas (Hipótese I).

A perspectiva de ação individual, em consonância com a Teoria da Escolha Racional e a Teoria da Agência, pode ser observada em virtude da presença ou ausência de incentivos - como recompensas e punições -, existência de mecanismos de monitoramento, de forma que seja possível analisar o comportamento mais ou menos cooperativo (ou mais ou menos competitivo) dos agentes (COÊLHO e FERNANDES, 2017; EVANS e RAUCH, 1999; LOTTA, PIRES e OLIVEIRA, 2014; LUPIA e MCCUBBINS, 1994; MOE, 1984; NISKANEN, 1971). Segundo a Teoria da Agência, a qual adota a premissa de comportamento oportunista dos indivíduos, quando há delegação de decisões para agentes cujos objetivos não estão alinhados aos objetivos do principal, o resultado esperado é um baixo nível de desempenho (FAMA e JENSEN, 1983). No entanto, o principal dispõe de instrumentos para minimizar esse conflito de interesses, tais como o monitoramento do comportamento do agente ou - quando o produto do seu trabalho pode ser mensurado - a adoção de incentivos positivos e negativos, respectivamente prêmios e punições (ALCHIAN e DEMSETZ, 1972). A aplicação da Teoria da Agência no campo da Administração Pública foi estudada, entre outros autores, por Moe (1984). Segundo este pesquisador, nos vários níveis hierárquicos da administração pública pode ser identificada uma série de relações do tipo principal-agente, tais como a relação entre os burocratas de alto e médio escalão e entre eles e seus subordinados (os que, neste trabalho, são denominados burocratas da linha de frente ou 
burocratas de nível de rua). Nestas relações hierárquicas, ocorrem importantes problemas informacionais, principalmente a seleção adversa e o risco moral. A seleção adversa refere-se às "informações ocultas", isto é, ao comportamento de uma das partes voltado a esconder informações, crenças e valores que poderiam induzir a outra parte a fazer escolhas diferentes. Já o risco moral trata de "ações ocultas": acontece quando uma das partes adota um comportamento oportunista, a exemplo de esquivar-se ou negligenciar suas responsabilidades (em inglês, shirking), pois avalia que o risco de sofrer uma punição é menor do que o benefício oriundo da conduta egoísta (MOE, 1984).

Portanto, no contexto da administração pública, caracterizado por rigidez, multiplicidade de principais e agentes envolvidos, assim como multiplicidade de objetivos, é possível prever que haverá dificuldades e custos elevados na aplicação desses mecanismos. Um exemplo de conduta da burocracia que desvia de suas finalidades é descrito por Niskanen (1971): os agentes da burocracia podem utilizar suas vantagens informacionais, com o intuito de pressionar os governos a aumentar o orçamento à disposição de seus órgãos na realização de programas e expansão de seus quadros de funcionários, analogamente ao que fazem os gerentes de departamentos de empresas privadas.

Para compreender a perspectiva de ação individual é importante ressaltar que, desde o início dos anos 1990, concomitantemente à onda de reformas que transformam o setor público de numerosos países do mundo ocidental industrializado, difunde-se no campo da administração pública uma ideologia hegemônica - denominada New Public Management - voltada à aplicação de modelos de gestão empresariais no âmbito da gestão pública com a finalidade de "reinventar o governo" (OSBORNE e GAEBLER, 1992). Entre os remédios contemplados para as reformas estão previstas medidas tais como a redução de custos, a desagregação de organizações governamentais tradicionais em agências regidas por contratos específicos, a fixação de metas de desempenho e indicadores de produtividade, a introdução de mecanismos de mercado ou quase mercado etc. (POLLITT, 1995). Nessa perspectiva, segundo Cline (2000), para que as políticas públicas sejam traduzidas eficazmente na fase de implementação, é necessário definir claramente os objetivos das policies e estabelecer mecanismos de controle e coordenação para alinhar os interesses de todos os atores envolvidos. Segundo essa lógica da ação individual-racional, coerente com a Teoria da Escolha Racional e com a Teoria da Agência, o indivíduo tende naturalmente a tomar decisões alinhadas com seus interesses pessoais, frequentemente desviantes dos objetivos organizacionais. Por conseguinte, faz-se necessário que a organização aplique incentivos e sanções para alinhar os comportamentos individuais com os interesses institucionais.

Cabe mencionar que na literatura existem outras teorias, a exemplo da Stewardship Theory, as quais defendem que, para explicar a dinâmica das relações principal-agente, é necessário contemplar valores como confiança, cooperação, envolvimento, reciprocidade relacional etc. Segundo essas teorias, os comportamentos dos envolvidos, embora não necessariamente altruístas, podem ser cooperativos, especialmente em longo prazo; e os agentes podem ser motivados por incentivos não somente extrínsecos - bônus, recompensas financeiras, multas etc. - mas também intrínsecos - reputação, autonomia, satisfação no trabalho, estabilidade etc. (DAVIS, SCHOORMAN e DONALDSON, 1997; DONALDSON e DAVIS, 1991; KLUVERS e TIPPETT, 2011; VAN SLYKE, 2006).

Outra abordagem a ser contemplada na análise da ação individual diz respeito a que os indivíduos interpretam a realidade e fazem escolhas com base em suas ideias, julgamentos, valores, crenças etc. Dito de outra forma, admite-se a existência de um conjunto de variáveis cognitivas, além da racionalidade, capazes de influenciar os atores sociais no processo de tomada de decisão e na sua atuação (ELMORE, 1979; LIMA e D'ASCENZI, 2013; MAYNARD-MOODY e MUSHENO, 2012, 2015; MULLER e SUREL, 2002).

Independentemente de adotar as premissas da Teoria da Agência ou da Stewardship Theory e de admitir a influência de variáveis cognitivas sobre os comportamentos dos indivíduos, a perspectiva de ação individual é relevante para analisar a atuação dos burocratas de nível de rua, e avaliar em que medida a existência de incentivos influencia os agentes na implementação de diferentes políticas públicas e no cumprimento das metas estabelecidas (CLINE, 2000; COÊLHO e FERNANDES, 2017; LUPIA e MCCUBBINS, 1994; OSBORNE e GAEBLER, 1992; POLLITT, 1995). Admite-se a relevância de incentivos - extrínsecos ou intrínsecos - na atuação de burocratas de nível de rua responsáveis pela implementação de políticas públicas. Logo, valendo-se dessas considerações, independentemente do comportamento do burocrata implementador, como "agente" ou como steward, supõe-se que a ação individual dos burocratas de nível de rua afeta a implementação de políticas públicas (Hipótese II).

Por fim, a perspectiva relacional estuda as múltiplas interações de agentes burocráticos com outros agentes internos e externos ao Estado. Por esse prisma, a atuação dos burocratas na implementação das políticas públicas é concebida dentro de um sistema de relações abrangente, o qual se apresenta articulado em redes (HUISING e SILBEY, 2011; LOTTA, 2010, 2014; 
LOTTA, PIRES e OLIVEIRA, 2014; PIRES, 2009). Keiser (2010, p. 251) considera as organizações burocráticas como "[...] parte de sistemas mais amplos de governança de organizações interligadas", e mostra, especificamente, como variabilidades na implementação de uma política pública podem ser explicadas tendo-se por base a interação recíproca e a troca de informações entre os burocratas da linha de frente e os demais agentes envolvidos (KEISER, 2010). Conforme apontado por Abers e Von Bülow (2011), atores internos ao Estado podem se tornar parte ativa de redes maiores que sejam promotoras de mudanças na formulação e na implementação de políticas públicas. Em outros termos, a construção de redes de ativismo social pode assumir configurações diferenciadas e perpassar as fronteiras entre as organizações da sociedade civil e o Estado, fugindo de formas e limites preestabelecidos (ABERS e VON BÜLOW, 2011). Coerentemente com esta visão, Viana (2017) defende que, para a compreensão da implementação de políticas públicas, é necessário incluir a análise das relações ativas que se desenvolvem entre burocratas e membros de movimentos sociais. Em estudo recente, no qual analisa a atuação dos vários atores envolvidos no programa Minha Casa Minha Vida - Entidades, o autor destaca o papel das entidades sociais e das famílias que se tornam protagonistas na implementação da política habitacional do Estado, participando na definição de suas próprias necessidades de moradia (VIANA, 2017). Neste processo, os burocratas, apesar de estarem sujeitos a vínculos de natureza legal, institucional e técnica, podem, por um lado, assumir o papel de negociadores com os escalões superiores do poder público, atuando estrategicamente como parceiros dos movimentos sociais; por outro lado, podem realizar a função de mediadores, tornando mais inteligíveis as decisões estatais para os membros das entidades e para os próprios usuários (VIANA, 2017).

Desta perspectiva relacional, Berk, Galvan e Hattam (2013) ressaltam a ação criativa dos agentes públicos promovendo processos de mudança incremental interna às próprias instituições; Huising e Silbey (2011) apontam que agentes implementadores, desenvolvendo suas capacidades de negociação, podem conseguir desempenhos superiores por meio da readaptação das normas ao contexto local; já Alexander, Lewis e Considine (2011) defendem que o estudo das interações entre políticos e burocratas e das diferentes configurações das redes pode permitir uma maior compreensão dos níveis de desempenho alcançados pelo governo, e da maior ou menor satisfação da sociedade com relação aos serviços prestados por instituições públicas locais.

No que diz respeito à importância das relações entre atores políticos, Coêlho, Cavalcante e Turgeon (2016), em seu estudo sobre os mecanismos de difusão de políticas públicas, descrevem como a influência exercida por certos governos na adoção de policies por outros governos propaga-se mediante redes formais ou informais.

Deduz-se das leituras que a análise das múltiplas relações dos agentes de nível de rua com os demais atores sociais (políticos, fiscais, usuários etc.) é fundamental para compreender a atuação da burocracia e o processo de implementação de policies. Objetivando analisar a atuação dos burocratas implementadores segundo a perspectiva relacional, será necessário avaliar a intensidade e a frequência das interações, bem como a qualidade e a quantidade das informações compartilhadas no programa em questão, pois, tais interações podem favorecer o aprendizado mútuo e o alinhamento de interesses, afetando o processo de implementação. Consequentemente, pode se supor que as interações dos burocratas de nível de rua entre si e com os demais atores envolvidos afetam a implementação de políticas públicas (Hipótese III).

Além das três perspectivas descritas acima, em cujas bases foram formuladas as respectivas hipóteses, precisam ser observados os fatores institucionais ligados às políticas públicas, tais como ambiente político, econômico, legal etc. (COÊLHO e FERNANDES, 2017; OLIVEIRA e ABRUCIO, 2011), cuja influência precisa ser analisada no âmbito da implementação de programas de políticas públicas. Apesar dos progressos registrados em algumas pesquisas (COÊLHO e FERNANDES, 2017; ZHAN, LO e TANG, 2013), pouco se sabe ainda sobre a magnitude do impacto de fatores exógenos na implementação de policies.

\section{JUSTIFICATIVA DA JUNÇÃO DAS DIFERENTES ABORDAGENS TEÓRICAS E APRESENTAÇÃO DO MODELO}

Neste ensaio, analisou-se a posição dos vários autores selecionados ao longo da pesquisa bibliográfica no interior de cada perspectiva analítica. Porém, entende-se que as diferentes perspectivas e as respectivas abordagens teóricas não se formaram isoladamente: os conceitos de cada uma, se interpretados de maneira mais aberta e flexível, ocupam uma dimensão transversal, como será demonstrado a seguir. Assim, neste trabalho, as três perspectivas analíticas - estrutural, de ação individual e relacional - foram colocadas numa relação dialética, o que permitiu uma visão para além das limitações de cada uma delas e, destarte, sua contribuição para o avanço do conhecimento sobre o tema. Para isso, procurou-se uma justificativa teórica que, baseada em estudos já empreendidos, auxiliasse os autores na tarefa de juntar visões aparentemente inconciliáveis. 
Com este intuito, toma-se um estudo de Lima e D’Ascenzi (2013, p. 105), o qual propõe uma compreensão mais fluida do conceito de implementação, que pode ser entendida como "[...] um processo de apropriação de uma ideia que [...] é consequência da interação entre a intenção (expressa no plano) e os elementos dos contextos locais de ação". Assim, a proposta desses autores contribui para uma integração entre dois modelos analíticos da implementação: o primeiro baseado numa abordagem sequencial, centrado nas normas e na formulação de políticas públicas, em que a implementação é concebida como operacionalização do plano no âmbito administrativo; o segundo modelo baseado num desenho retrospectivo, orientado pela discricionariedade dos implementadores, que se esforçam em adaptar o plano ao contexto local (LIMA e D'ASCENZI, 2013). Para conciliar as duas abordagens, segundo Lima e D’Ascenzi (2013, p. 105), é necessário compreender o plano de maneira mais aberta e flexível, como um "conjunto de disposições" que orientam um processo de experimentação. De fato, o plano é posto à prova somente por meio de sua implementação (antes disso, ele existe no nível meramente potencial) e o próprio processo de implementação pode gerar novos insights capazes de aprimorar as propostas contidas inicialmente no plano. Deste ponto de vista, elementos da dimensão estrutural como normas, regras formais e planos podem ser entendidos como objetos socialmente construídos, e, como tais, sujeitos a contínuas mudanças e adaptações por efeito da agência humana (BARRETT, 2004). Os planos também, antes de serem executados, precisam ser interpretados pelos agentes (agency), que, para isso, se servem de seu conjunto de ideias, crenças e valores (variáveis cognitivas); por fim, os planos são mediados por regras e estruturas organizacionais e moldados pelas relações de poder estabelecidas no ambiente de trabalho (LIMA e D'ASCENZI, 2013). Isso permite compreender como, no âmbito de um sistema complexo como a implementação de políticas públicas, a dimensão estrutural se confronta e se renova, numa tensão dialética, no seu embate permanente com a ação individual - ou agência (BARRETT, 2004), extrapolando o âmbito da escolha racional e abrangendo variáveis cognitivas, como ideias e valores - e com as múltiplas relações estabelecidas no interior de um dado ambiente organizacional e fora dele.

Adicionalmente, é importante frisar que, na atualidade, o processo de implementação de políticas públicas é caracterizado pela existência de novos arranjos ou formas híbridas (MÉNARD, 2012). Em tais configurações organizacionais, as estruturas hierárquicas tradicionais da burocracia pública convivem e se misturam com mecanismos de mercado (perspectiva individualcompetitiva) e com redes de organizações de nível de rua e de atores públicos e privados, a exemplo de empresas, associações da sociedade civil, grupos sociais e de usuários etc. (perspectiva relacional-interativa). Configuram-se, assim, arranjos híbridos nos quais as fronteiras entre as diferentes organizações/agentes envolvidos se tornam menos nítidas: por exemplo, os prestadores de serviço de empresas terceirizadas estão inseridos nas equipes de trabalho da entidade pública e os funcionários públicos podem atuar como supervisores ou fiscais dos serviços prestados por empresas privadas (BRODKIN, 2015; CAVALCANTI, LOTTA e PIRES, 2018; THOMANN, HUPE e SAGER, 2018).

É importante também mencionar pesquisas nacionais recentes, como a de Ferreira e Medeiros (2016), que admitem a utilização de perspectivas diferentes na identificação dos fatores que moldam o comportamento do implementador de nível de rua. Segundo eles, variáveis como discricionariedade, normas, autointeresse etc. são compatíveis e se influenciam mutuamente no próprio processo de implementação (FERREIRA e MEDEIROS, 2016).

Com base no entendimento dos estudos citados, especialmente o de Lima e D’Ascenzi (2013), cujo posicionamento encontra respaldo em autores internacionais como Majone e Wildavsky (1984) e Barrett (2004), o artigo de Ferreira e Medeiros (2016) e os trabalhos já citados sobre a existência de arranjos híbridos e a atuação de street-level organizations na execução de políticas públicas, entende-se que é possível revisitar alguns conceitos centrais da literatura sobre implementação e interpretar de forma mais fluida as abordagens que os sustentam. Planos, normas e estruturas podem ser concebidos como potencialidades ou conjuntos de intenções a serem continuamente interpretados, aceitos e aprimorados pelos atores envolvidos (LIMA e D'ASCENZI, 2013); a ação individual pode ser compreendida como agency explicada não somente por incentivos, mas também por valores, ideias, ideologias, julgamentos etc., como defendido por Maynard-Moody e Musheno (2012, 2015); e as interações podem ser entendidas como constitutivas de relações cooperativas (LOTTA, 2014, 2018) ou conflitivas, entre atores de natureza diferente, portadores de múltiplos papéis e responsáveis por alcançar objetivos contraditórios (CHUN e RAINEY, 2005; DIXIT, 2002). A releitura crítica desses conceitos permite aproximar, dialeticamente, as abordagens teóricas nas quais eles se baseiam, justificando, assim, a justaposição das respectivas dimensões analíticas, a saber, a perspectiva estrutural, a de ação individual e a relacional, e sua síntese dialética em um único modelo analítico.

A título de contribuição para o conhecimento sobre o tema, este estudo propõe que pesquisas futuras adotem uma visão dialética e integradora das três perspectivas analíticas, com o intuito de testar no plano empírico que, no dia a dia dos streetlevel bureaucrats, a necessidade de aderir às normas e às estruturas postas, a ação individual dos agentes e suas interações 
recíprocas e com outros atores sociais convivem e se influenciam mutuamente no complexo processo de tomada de decisão que permeia a prestação de serviços públicos para os cidadãos. Assim, supõe-se que a aderência a regras e estruturas estabelecidas, a ação individual dos burocratas de nível de rua e suas interações - entre si e com os demais atores envolvidos - afetam conjuntamente a implementação de políticas públicas (Hipótese IV).

Portanto, para uma análise expandida da atuação dos burocratas de nível de rua na implementação de políticas públicas nacionais, propõe-se a adoção de um construto teórico sintetizado no modelo reportado na Figura 1, que, identificando as principais dimensões e categorias conceituais levantadas neste trabalho, busca integrar as três perspectivas analíticas apresentadas.

Figura 1

Modelo para uma análise expandida da atuação dos burocratas implementadores

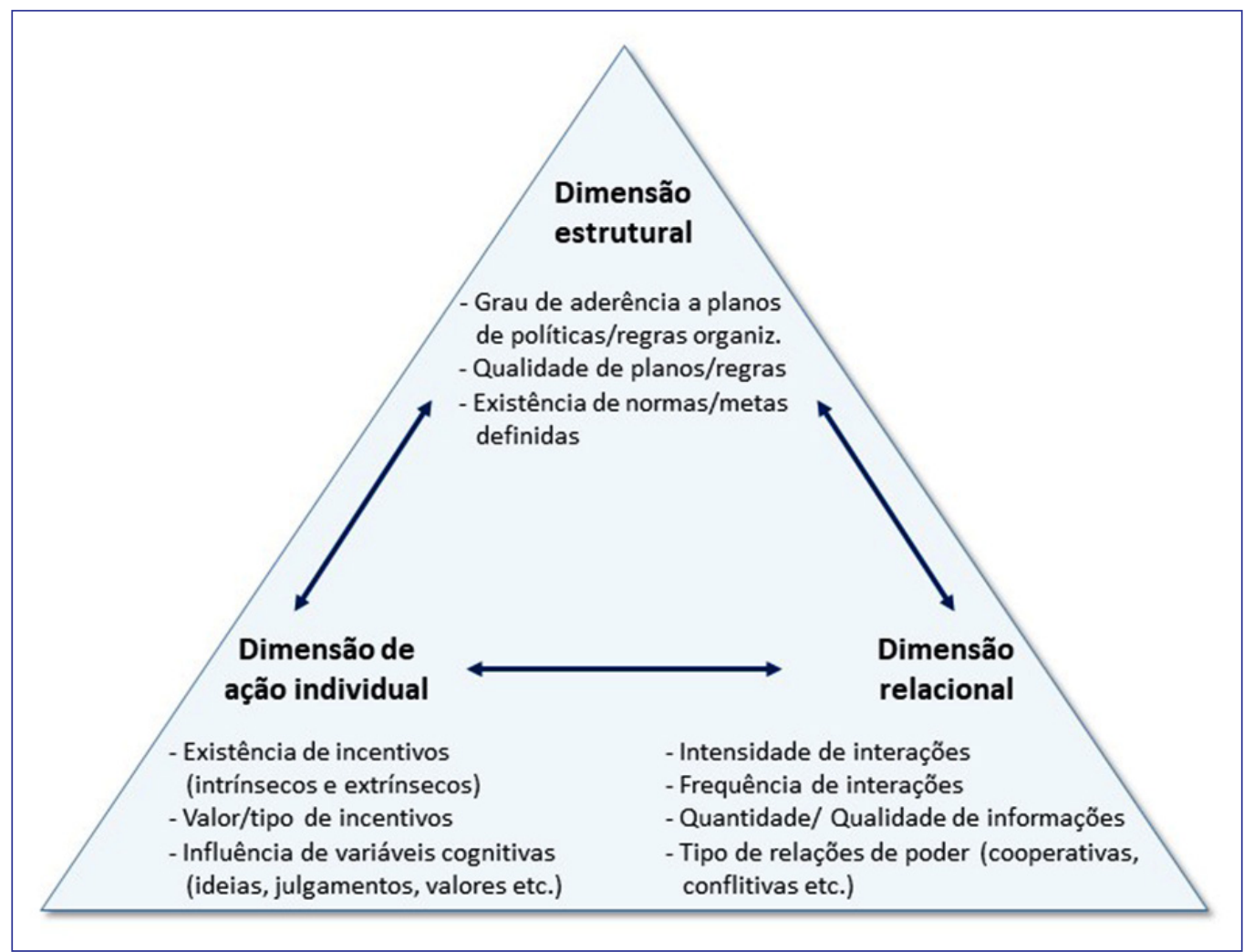

Fonte: Elaborado pelos autores.

\section{CONSIDERAÇÕES FINAIS}

A pesquisa bibliográfica realizada permitiu consolidar a compreensão da importância do debate - conduzido em âmbito nacional e internacional - entre regras e discricionariedade na implementação de políticas públicas, tanto no plano teórico quanto no plano empírico.

No plano teórico, este trabalho permitiu formular pressupostos que visam formar uma análise expandida da atuação dos burocratas implementadores e do próprio processo de implementação, baseados no reconhecimento da justaposição e da compatibilidade de perspectivas teóricas diferentes, consideradas, até a atualidade, pelo menos em âmbito nacional, como mutuamente excludentes nas pesquisas sobre o tema. Acredita-se que a principal contribuição deste trabalho consiste em ter proposto, por meio de um construto teórico inédito, a compatibilidade e a integração de três diferentes abordagens em um único construto teórico. 
A verificação desses pressupostos no plano empírico requer análises comparativas entre diferentes programas de políticas públicas nacionais e entre diversos perfis de burocratas, quanto a capacidades, formação, modalidades de ingresso no serviço público, rotinas de trabalho, constrangimentos externos etc. Os perfis desses burocratas e sua atuação no processo de implementação poderão ser mais bem compreendidos avaliando-se sua maior ou menor proximidade do cidadão e considerando-se especialmente o tipo de poder exercido, o qual, a depender da política, pode oscilar entre a garantia de benefícios e a entrega de serviços aos usuários (como acontece no caso de agentes de saúde, assistentes sociais, professores, entre outros) e a inibição e/ou repressão de irregularidades/ilícitos mediante o exercício da fiscalização e da coerção (como acontece no caso de policiais, auditores da Receita Federal ou de fiscais de agências reguladoras que atuam nas áreas de meio ambiente, agricultura, vigilância sanitária, entre outras).

Nesse sentido, pesquisas futuras poderão permitir o teste do modelo em diferentes contextos empíricos por meio de análises comparativas, como estudos de casos múltiplos, que, por exemplo, avaliem como as diferentes perspectivas analíticas da atuação dos burocratas de nível de rua se traduzem na prática, comparando agentes com perfis diferenciados que atendem diferentes categorias de usuários ou garantem a defesa de interesses difusos.

Vale destacar que, atualmente, no Brasil, a maior parte dos estudos têm focado na análise de burocratas implementadores que pertencem à primeira tipologia (entregadores de serviços públicos, que escolhem e/ou atendem os beneficiários). Não foi possível identificar na pesquisa bibliográfica realizada neste trabalho estudos nacionais que tenham analisado prioritariamente burocratas da linha de frente cuja atuação esteja voltada a inibir condutas de cidadãos infratores. Nessa linha de raciocínio, o modelo proposto permitirá avaliar em que medida cada uma das perspectivas contribui para a execução de dada política pública. Pode-se supor que agentes da linha de frente mais voltados para a ação fiscalizadora e sancionadora estejam mais propensos para a adesão às regras e às estruturas formais em comparação com agentes mais voltados para a alocação de benefícios entre cidadãos elegíveis. Por outro lado, não é possível excluir a priori que a atuação desses mesmos agentes possa ser influenciada pela existência de incentivos (financeiros ou não) e/ou pelas interações com outros atores sociais públicos ou privados.

Adicionalmente este estudo apontou a necessidade de compreender a relação entre fatores associados às dimensões da atuação dos burocratas de nível de rua e a forma como a política pública é implementada, ao ponto de ser adaptada, ou não, ao contexto local e/ou à situação fática, afetando assim a própria natureza da política. Torna-se, então, necessário conduzir investigações que avaliem no nível micro os fenômenos que afetam o processo de implementação em diferentes circunstâncias.

Assim, uma possível aplicação do construto teórico proposto pode consistir na análise da relação entre competências/ características - intelectuais, emocionais, cognitivas etc. - de um dado perfil de burocrata de nível de rua e o tipo de política a ser implementada. Pode-se supor, por exemplo, que, para uma policy que precisa ser adaptada ao contexto local, a perspectiva relacional e certas variáveis da perspectiva da ação individual possam assumir um peso preponderante na atuação do burocrata de nível de rua, em comparação com a perspectiva estrutural. Vice-versa, para uma política que pretenda ser mais estandardizada, supõe-se que a perspectiva estrutural prevaleça.

Trata-se, evidentemente, de hipóteses de trabalho formuladas tendo-se por base o construto teórico proposto, mas que precisam ser testadas no plano empírico.

Outras análises da atuação dos burocratas implementadores podem comparar os efeitos de diferentes contextos políticosinstitucionais sobre o mesmo programa de policy em cortes temporais distintos. Por exemplo, pode-se investigar como as diferentes orientações políticas do núcleo de governo, tomadas em diferentes mandatos presidenciais no Brasil, afetam a atuação dos burocratas implementadores em diferentes áreas de políticas públicas. Assim, é oportuno refletir sobre a necessidade de desenvolver estudos que visem aos setores de policies ainda pouco explorados, a exemplo de agricultura, meio ambiente, trabalho e emprego, entre outros.

Ainda, tendo em vista a introdução de reformas legislativas voltadas a ampliar o envolvimento de organizações não estatais - denominadas na literatura mais recente organizações de nível de rua - na provisão de serviços públicos, mediante a utilização crescente de arranjos híbridos públicos-privados, considera-se oportuno investigar como as dimensões propostas no modelo se aplicam e se articulam na atuação dos burocratas de nível de rua e das organizações prestadoras de serviços e, consequentemente, em que medida afetam a forma como as políticas públicas são implementadas e entregues aos cidadãos.

Este trabalho apresenta uma série de limitações que podem constituir aspectos a serem mais bem desenvolvidos em pesquisas futuras, a saber: 
- Necessidade de ampliar a pesquisa bibliográfica, recorrendo a, além dos autores já contemplados, situados principalmente nos campos da Ciência Política e da Administração Pública, outros autores do campo da Sociologia. Entre eles, vale mencionar Vincent Dubois (1999), que desenvolveu uma abordagem crítica sobre análise de políticas públicas; Flávio Eiró (2017), que analisou a influência das opiniões dos agentes implementadores sobre o exercício da discricionariedade; e outros autores que estudam as consequências sociais da implementação, a exemplo das desigualdades (CAVALCANTI, LOTTA e PIRES, 2018);

- Aprofundamento do cotejamento das três perspectivas apresentadas (estrutural, de ação individual e relacional), por meio da apresentação de vantagens e desvantagens de cada uma delas, do ponto de vista da implementação de policies;

- Escolha da metodologia mais apropriada para analisar - em pesquisas futuras - o processo de implementação de certa política e, eventualmente, avaliar seu desempenho do ponto de vista de sua efetividade, considerando que uma policy bem executada não necessariamente satisfaz plenamente o usuário;

- Aprofundamento da discussão sobre a qualidade de regras, o estudo de incentivos, distinguindo entre incentivos extrínsecos e intrínsecos, e as variáveis cognitivas e como todos esses fatores, tomados separadamente ou em conjunto, podem afetar os comportamentos dos burocratas implementadores;

- Compreensão mais profunda da importância do burocrata de carreira para o Estado e para a Sociedade, de seu papel, de seus valores, ideias, outros aspectos cognitivos e das características que o capacitam para a implementação de políticas públicas, especialmente no contexto atual caracterizado por novos arranjos públicos-privados.

No Brasil, existe a necessidade de desenvolver estudos empíricos que permitam compreender mais profundamente o papel da burocracia - principalmente a de nível de rua - e de outros atores públicos e privados na execução de diferentes policies e que forneçam soluções inovadoras para o processo de tomada de decisão na fase de implementação. Acredita-se que pesquisas conduzidas nas linhas apontadas neste trabalho podem não somente contribuir para os necessários avanços teóricos no campo da Administração Pública nacional, mas também na formulação de soluções para o aprimoramento, qualificação e inovação do processo decisório dos agentes do Estado, e dos demais atores sociais envolvidos, na implementação de políticas públicas. 
A atuação dos burocratas de nível de rua na implementação de políticas públicas no Brasil: uma proposta de análise expandida
Francesco Bonelli| Antonio Sérgio Araújo Fernandes Denilson Bandeira Coêlho | Jamili da Silva Palmeira

\section{REFERÊNCIAS}

ABERS, R.; VON BÜLOW, M. Movimentos sociais na teoria e na prática: como estudar o ativismo através da fronteira entre estado e sociedade? Sociologias, v. 13, n. 28, p. 52-84, 2011.

ALCHIAN, A. A.; DEMSETZ, H. Production, information costs, and economic organization. The American Economic Review, v. 62, n. 5, p. 777-795, 1972.

ALEXANDER, D.; LEWIS, J. M.; CONSIDINE, M. How politicians and bureaucrats network: a comparison across governments. Public Administration, v. 89, n. 4, p. 1274-1292, 2011.

BARRETT, S. M. Implementation studies: time for a revival? Personal reflections on 20 years of implementation studies. Public Administration, v. 82, n. 2, p. 249-262, 2004.

BERK, G.; GALVAN, D. C.; HATTAM, V. (Eds.). Political creativity: reconfiguring institutional order and change. Pennsylvania: University of Pennsylvania Press, 2013.

BRODKIN, E. The inside story. In: HUPE, P.; HILL, M.; BUFFAT, A. (Eds.). Understanding street level bureaucracy. Bristol: Policy Press, 2015. Part One, Introdc.

CAVALCANTI, S.; LOTTA, G. S.; PIRES, R. R. C. Contribuições dos estudos sobre burocracia de nível de rua. In: PIRES, R.; LOTTA, G.; OLIVEIRA, V. E. (Orgs.). Burocracia e políticas públicas no Brasil: interseções analíticas. Brasília: Ipea/ Enap, 2018. cap. 9, p. 227-246.

CHUN, Y. H.; RAINEY, H. G. Goal ambiguity and organizational performance in US federal agencies. Journal of Public Administration Research and Theory, v. 15, n. 4, p. 529-557, 2005.

CLINE, K. D. Defining the implementation problem: Organizational management versus cooperation. Journal of Public Administration Research and Theory, v. 10, n. 3, p. 551-572, 2000.

COÊLHO, D. B.; CAVALCANTE, P.; TURGEON, M. Mecanismos de difusão de políticas sociais no Brasil: uma análise do Programa Saúde da Família. Revista de Sociologia e Política, v. 24, n. 58, p. 145-165, 2016.

COÊLHO, D. B.; FERNANDES, A. S. A. Rules matter: determinants of bureaucratic control in the Bolsa Família Program. RAP - Brazilian Journal of Public Administration, v. 51, n. 5, p. 689-707, 2017.

CURRIE, G.; PROCTER, S. J. The antecedents of middle managers' strategic contribution: the case of a professional. Journal of Management Studies, v. 42, n. 7, p.99-117, 2005.

DAVIS, J, H.; SCHOORMAN, F. D.; DONALDSON, L. Toward a Stewardship Theory of Management. Academy of Management Review, v. 22, n. 1, p. 20-47, 1997.

DAVIS, K. C. Discretionary justice. Baton Rouge: Louisiana State University Press, 1969.

DELEON, P. The missing link revisited: contemporary implementation research. Review of Policy Research, v. 16, n. 3-4, p. 311-338, 1999.

DIXIT, A. Incentives and organizations in the public sector: an interpretative review. Journal of Human Resources, v. 37, n. 4, p. 696-727, 2002.

DONALDSON, L.; DAVIS, J. H. Stewardship theory or agency theory: CEO governance and shareholder returns. Australian Journal of management, v. 16, n. 1, p. 49-64, 1991.
DUBOIS, V. La vie au guichet: relation administrative et traitement de la misère. Paris: Economica, 1999. (Collection Études Politiques).

EIRÓ, F. O Programa Bolsa Família e os pobres "não merecedores": poder discricionário e os limites da consolidação de direitos sociais. In: IPEA - Instituto de Pesquisa Econômica Aplicada. Implementação de políticas e desigualdades. Boletim de Análise Político-Institucional, n. 13,2017 . p. $65-70$.

ELMORE, R. F. Backward mapping: Implementation research and policy decisions. Political Science Quarterly, v. 94, n. 4, p. 601-616, 1979.

EVANS, P. B. Embedded autonomy: states and industrial transformation. Princeton: Princeton University Press, 1995.

EVANS, P. B.; RAUCH, J. E. Bureaucracy and growth: a cross-national analysis of the effects of "Weberian" state structures on economic growth. American Sociological Review, v. 64, n. 5, p. 748-765, 1999.

FAMA, E. F.; JENSEN, M. C. Separation of ownership and control. Journal of Law and Economics, v. 26, n. 2, p. 301-325, 1983.

FARIA, C. A. P. Ideias, conhecimento e políticas públicas: um inventário sucinto das principais vertentes analíticas recentes. Revista Brasileira de Ciências Sociais, v. 18, n. 51, p. 21-30, 2003.

FARIA, C. A. P. Introdução. In: FARIA, C. A. P. (Org.). Implementação de políticas públicas: teoria e prática. Belo Horizonte: Ed. PUC Minas, 2012. p. 7-18.

FERREIRA, V. D. R. S.; MEDEIROS, J. J. Fatores que moldam o comportamento dos burocratas de nível de rua no processo de implementação de políticas públicas. Cadernos EBAPE.BR, Rio de Janeiro, v. 14, n. 3, p. 776-793, 2016.

FLOYD, S. W.; WOOLDRIDGE, B. Middle management involvement in strategy and its association with strategic type: a research note. Strategic Management Journal, v. 13, n. S1, p. 153-167, 1992.

GIDDENS, A. The Constitution of Society. Oxford: Polity Press, 1994.

GIL, A. C. Como elaborar projetos de pesquisa. 4. ed. São Paulo: Atlas, 2007.

GRAY, D. E. Pesquisa no mundo real. Tradução: Roberto Cataldo Costa. Revisão técnica: Dirceu da Silva. 2. ed. Porto Alegre: Penso, 2012

HAM, C.; HILL, M. O processo de elaboração de políticas no estado capitalista moderno. Tradução: Renato Amorim e Renato Dagnino. Adaptação e revisão: Renato Dagnino. Campinas: DPCT-UNICAMP, 1993.

HILL, H. C. Understanding implementation: street-level bureaucrats' resources for reform. Journal of Public Administration Research and Theory, v. 13, n. 3, p. 265-282, 2003.

HODGSON, G. M. What are institutions? Journal of Economic Issues, v. 40 , n. 1, p. 1-25, 2006.

HUISING, R.; SILBEY, S. S. Governing the gap: forging safe science through relational regulation. Regulation \& Governance, v. 5, n. 1 , p. 14-42, 2011.

HUPE, P.; HILL, M. Street-Level bureaucracy and public accountability. Public Administration, v. 85, n. 2, p. 279-299, 2007. 
A atuação dos burocratas de nível de rua na implementação de políticas públicas no Brasil: uma proposta de análise expandida
Francesco Bonelli| Antonio Sérgio Araújo Fernandes Denilson Bandeira Coêlho | Jamili da Silva Palmeira
KEISER, L. R. Understanding street-level bureaucrats' decision making: determining eligibility in the social security disability program. Public Administration Review, v. 70, n. 2, p. 247-257, 2010.

KLUVERS, R.; TIPPETT, J. An exploration of stewardship theory in a Not-for-Profit organisation. Accounting Forum, v. 35, n. 4, p. 275284, 2011.

LIMA, L. L.; D’ASCENZI, L. Implementação de políticas públicas. Revista de Sociologia e Política, v. 21, n. 48, p. 101-110, 2013.

LIPSKY, M. Street-level bureaucrats. Nova York: Russel Sage, 1980.

LOTTA, G. S. Implementação de políticas públicas: o impacto dos fatores relacionais e organizacionais sobre a atuação dos burocratas de nível de rua no Programa Saúde da Família. 2010. Tese (Doutorado em Ciência Política) - Faculdade de Filosofia, Letras e Ciências Humanas, Universidade de São Paulo, São Paulo, 2010.

LOTTA, G. S. Agentes de implementação: uma forma de análise de políticas públicas. Cadernos Gestão Pública e Cidadania, v. 19, n. 65, p. 186-206, 2014.

LOTTA, G. S. Burocracia, redes sociais e interação: uma análise da implementação de políticas públicas. Revista de Sociologia e Política, v. 26, n. 66, p. 143-173, 2018.

LOTTA, G. S.; PIRES, R. R. C.; OLIVEIRA, V. E. Burocratas de médio escalão: novos olhares sobre velhos atores da produção de políticas públicas. Revista do Serviço Público, v. 65, n. 4, p. 463-492, 2014.

LUPIA, A.; MCCUBBINS, M. D. Learning from oversight: fire alarms and police patrols reconstructed. Journal of Law, Economics \& Organization, v. 10, n. 1, p. 96-125, 1994.

MAJONE, G.; WILDAVSKY, A. B. Implementation as evolution. In: PRESSMAN, J. L.; WILDAVSKY, A. B. (Eds.). Implementation. 3. ed. Berkeley: University of California Press, 1984.

MARCH, J. G.; OLSEN, J. P. The Logic of Appropriateness. In: GOODIN, R. E.; MORAN, M.; REIN M. (Eds.). The Oxford Handbook of Public Policy. Oxford, NY: Oxford University Press, 2006.

MATLAND, R. E. Synthesizing the implementation literature: The ambiguity-conflict model of policy implementation. Journal of Public Administration Research and Theory, v. 5, n. 2, p. 145-174, 1995.

MAY, P. J.; WINTER, S. C. Politicians, managers, and street-level bureaucrats: Influences on policy implementation. Journal of Public Administration Research and Theory, v. 19, n. 3, p. 453-476, 2007.

MAYNARD-MOODY, S.; MUSHENO, M. State agent or citizen agent: Two narratives of discretion. Journal of Public Administration Research and Theory, v. 10, n. 2, p. 329-358, 2000.

MAYNARD-MOODY, S.; MUSHENO, M. Social equities and inequities in practice: street-level workers as agents and pragmatists. Public Administration Review, v. 72, n. s1, p. 16-23, 2012.

MAYNARD-MOODY, S.; MUSHENO, M. Playing the rules: discretion in social and policy context. In: HUPE, P.; HILL, M.; BUFFAT, A. (Eds.). Understanding street-level bureaucracy. Bristol: Policy Press, 2015. p. 169-186.

MÉNARD, C. Hybrid modes of organization. Alliances, joint ventures, networks, and other 'strange' animals. In: GIBBONS, R.; ROBERTS, J. (Eds.). The Handbook of Organizational Economics. Princeton: Princeton University Press, 2012. p. 1066-1108.
MOE, T. M. The new economics of organization. American Journal of Political Science, v. 28, n. 4, p. 739-777, 1984.

MULLER, P.; SUREL, Y. A análise das políticas públicas. Pelotas: Educat, 2002.

NISKANEN, W. A. Bureaucracy and representative government. Chicago: Aldine Atherton, 1971.

OLIVEIRA, A. Burocratas da linha de frente: executores e fazedores das políticas públicas. Revista de Administração Pública, Rio de Janeiro, v. 46, n. 6, p. 1551-1573, 2012.

OLIVEIRA, V. E.; ABRUCIO, F. L. Entre a política e a burocracia: a importância dos burocratas de nível médio para a produção de políticas públicas em saúde e educação. In: ENCONTRO ANUAL DA ANPOCS, 35., 2011, Caxambu (MG). Anais... Minas Gerais: ANPOCS, 2011.

OSBORNE, D.; GAEBLER, T. Reinventing government: how the entrepreneurial spirit is transforming the public sector. Reading: Addison-Wesley, 1992.

O'TOOLE JUNIOR, L. J. Rational choice and policy implementation: Implications for interorganizational network management. The American Review of Public Administration, v. 25, n. 1, p. 43-57, 1995.

O'TOOLE JUNIOR, L. J. Research on policy implementation: Assessment and prospects. Journal of Public Administration Research and Theory, v. 10, n. 2, p. 263-288, 2000.

PARSONS, W. Public policy: an introduction to the theory and practice of policy analysis. Cheltenham: Edward Elgar, 1995.

PEREIRA, L. C. B.; MOTTA, F. C. P. Introdução à organização burocrática. São Paulo: Brasiliense, 1987.

PIRES, R. R. C. Burocracia, discricionariedade e democracia: alternativas para o dilema entre controle do poder administrativo e capacidade de implementação. Cadernos Gestão Pública e Cidadania, v. 14, n. 54, p. 147-187, 2009.

POLLITT, C. Justification by works or by faith? Evaluating the new public management. Evaluation, v. 1, n. 2, p. 133-154, 1995.

PRESSMAN, J. L.; WILDAVSKY, A. B. Implementation: how great expectations in Washington are dashed in Oakland; or, why it's amazing that federal programs work at all. Berkeley: University of California Press, 1973.

SAETREN, H. Implementing the third generation research paradigm in policy implementation research: An empirical assessment. Public Policy and Administration, v. 29, n. 2, p. 84-105, 2014.

THOMANN, E.; HUPE, P.; SAGER, F. Serving many masters: Public accountability in private policy implementation. Governance, v. 31, n. 2, p. 299-319, 2018.

VAN METER, D. S.; VAN HORN, C. E. The policy implementation process: A conceptual framework. Administration \& Society, v. 6, n. 4, p. 445-488, 1975.

VAN SLYKE, D. M. Agents or stewards: Using theory to understand the government-nonprofit social service contracting relationship. Journal of Public Administration Research and Theory, v. 17, n. 2, p. 157-187, 2006.

VIANA, R. R. Reconfigurando a relação entre estado - sociedade: um olhar para ação dos diferentes atores no processo de produção do Programa Minha Casa Minha Vida-Entidades. In: ENCONTRO DA ANPAD, 
A atuação dos burocratas de nível de rua na implementação de políticas públicas no Brasil: uma proposta de análise expandida
Francesco Bonelli | Antonio Sérgio Araújo Fernandes Denilson Bandeira Coêlho | Jamili da Silva Palmeira
41., 2017, São Paulo. Anais eletrônicos... São Paulo: ANPAD, 2017. Disponível em: <http://www.anpad.org.br/ anpad/eventos.php?cod_ evento=1\&cod_evento_edicao=89\&cod_edicao_subsecao=1453\&cod_ edicao_trabalho=23081>. Acesso em: 15 out. 2017.

WEBER, M. Economy and society. New York: Bedminster Press, 1968.

WILLIAMSON, O. E. The economic institutions of capitalism: firms, markets, relational contracting. New York: Free Press, 1985.

WILLIAMSON, O. E. The mechanisms of governance. Oxford: Oxford University Press, 1996.

WILSON, J. Q. The bureaucracy problem. The Public Interest, n. 6, p. 3-9, 1967. Disponível em: <https://nationalaffairs.com/public_ interest/detail/the-bureaucracy-problem>. Acesso em: 30 out. 2018.
WILSON, W. The study of administration. Political Science Quarterly, v. 2, n. 2, p. 197-222, 1887.

WISE, L. R. Bureaucratic Posture: On the Need for a Composite Theory of Bureaucratic Behavior. Public Administration Review, v. 64, n. 6, p. 669-680, 2004.

ZAHARIADIS, N. The multiple streams framework: Structure, limitations, prospects. In: SABATIER, P. A.; WEIBLE, C. M. (Eds.). Theories of the policy process. 2. ed. Boulder: Westview Press Boulder, 2007. p. 65-92.

ZHAN, X.; LO, C. W. H.;TANG, S. Y. Contextual changes and environmental policy implementation: a longitudinal study of street-level bureaucrats in Guangzhou, China. Journal of Public Administration Research and Theory, v. 24, n. 4, p. 1005-1035, 2013.

Francesco Bonelli

ORCID: https://orcid.org/0000-0001-8628-9068

Doutorando em Administração pelo Núcleo de Pós-Graduação em Administração da Universidade Federal da Bahia (NPGA/EA-UFBA); Mestre em Administração pelo Núcleo de Pós-Graduação em Administração da Universidade Federal da Bahia (NPGA/EA-UFBA); Professor do Instituto Federal de Educação, Ciência e Tecnologia da Bahia (IFBA); Administrador na Universidade Federal da Bahia (UFBA), Salvador - BA, Brasil. E-mail: francescobonelli@gmail.com

Antonio Sérgio Araújo Fernandes

ORCID: https://orcid.org/0000-0002-4171-7759

Doutor em Ciência Política pela Universidade de São Paulo (USP); Mestre em Desenvolvimento Urbano pela Universidade Federal de Pernambuco (UFPE); Professor Associado e Pesquisador do Núcleo de Pós-Graduação em Administração da Universidade Federal da Bahia (NPGA/EA-UFBA), Salvador - BA, Brasil.

E-mail: asaferna@outlook.com

Denilson Bandeira Coêlho

ORCID: https://orcid.org/0000-0003-0125-4347

Doutor e Mestre em Ciência Política pela Universidade Federal de Pernambuco (UFPE); Professor Associado I do Instituto de Ciência Política da Universidade de Brasília (IPOL/UnB), Brasília - DF, Brasil. E-mail: denilsonbc@unb.br

Jamili da Silva Palmeira

ORCID: https://orcid.org/0000-0002-6726-7258

Bolsista do Conselho Nacional de Desenvolvimento Científico e Tecnológico (CNPq); Mestranda em Administração pelo Núcleo de Pós-Graduação em Administração da Universidade Federal da Bahia (NPGA/EA-UFBA), Salvador - BA, Brasil. E-mail: jamilipalmeira.adm@gmail.com 